\title{
Who are the poor? Who are the rich? Evidence for Portugal
}

\section{Nuno Crespo}

Economics Department, Instituto Universitário de Lisboa (ISCTE - IUL), ISCTE Business School and UNIDE - IUL (Business Research Unit), Lisbon, Portugal

Sandrina B. Moreira

Department of Economics and Management, Instituto Politécnico de Setúbal (ESCE - IPS) and UNIDE - IUL (Business Research Unit), Setubal, Portugal, and

Nádia Simões

Economics Department, Instituto Universitário de Lisboa (ISCTE - IUL), ISCTE Business School and UNIDE - IUL (Business Research Unit), Lisbon, Portugal

\begin{abstract}
Purpose - The purpose of this paper is to identify the main determinants of the probability of a household being poor, middle class, or rich.

Design/methodology/approach - A new and integrated approach to the measurement of inequality in income distribution, poverty, and richness was recently proposed. Based on that approach and considering data for the Portuguese economy, the authors estimate a multinomial model in order to identify the main determinants of the probability of a household being poor, middle class, or rich using a set of characteristics of the households and the household's individual of reference as explanatory variables.

Findings - The evidence obtained indicates that: the determinants of poverty and richness are similar in qualitative terms; and household type, main source of income, education, and labor market state are the most important factors explaining these phenomena.

Originality/value - Following a methodology recently proposed by Crespo et al. toward an integrated measurement of inequality, poverty, and richness, the present study contributes to this line of research by using a micro-econometric model applied to the Portuguese economy in order to identify the determinants of poverty and richness.
\end{abstract}

Keywords Poverty, Richness, Portugal, Determinants

Paper type Research paper

\section{Introduction}

Income inequality and poverty are well established research fields in economics, including their measurement and the analysis of their determinants (Cowell, 2011). The analysis of these phenomena can be justified on several grounds. First, there is a natural wish to study an issue which is perceived as socially unfair. Second, economic

The authors thank the Office of National Statistics (INE) for kindly providing them with the survey data and acknowledge the financial support from the FCT PEst-OE/EGE/UI0315/2011. The usual disclaimer applies.

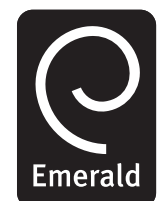

International Journal of Social Economics

Vol. 40 No. 6, 2013 pp. $579-590$ 
IJSE

40,6

580 policy concerns have brought the topic of poverty and inequality to the public debate arena. A deeper knowledge of the dimension and characterization of these phenomena is thus especially important in finding more effective socio-economic policies.

More recently, the study of the top income classes has also emerged with several detailed studies for distinct countries (Piketty, 2005; Piketty and Saez, 2006; Bach et al., 2009; Atkinson and Piketty, 2010; Atkinson et al., 2011). Analyzing the determinants of these phenomena is a complex task that has been addressed using either macro-level determinants or household and individual-level characteristics (Haughton and Khandker, 2009; Roine et al., 2009; Peichl and Pestel, 2010).

Following a methodology recently proposed by Crespo et al. (2012) toward an integrated measurement of inequality, poverty, and richness, the present study contributes to this line of research by using a micro-econometric model applied to the Portuguese economy in order to identify the determinants of poverty and richness.

This paper is structured as follows. Section 2 synthesizes the methodology that is taken as reference to measure inequality and to define the income groups. Section 3 characterizes households with respect to their position in the income distribution. Section 4 presents some final remarks.

\section{Defining income groups}

\subsection{Methodological options}

Measuring income inequality, poverty, and richness requires making choices about some methodological issues. We highlight four such issues. The first one concerns the choice of the indicator of resources. Cowell (2011) suggests that wealth, lifetime income, and income are, in that order, the most adequate ones. Data limitations usually imply the use of income. Regarding the concept of income, the most common option is the monetary disposable income. However, this choice is not immune to criticism because of the exclusion of non-monetary forms of income. Therefore, we assume total income (i.e. monetary and non-monetary) as the indicator of resources.

A second methodological choice relates to the demographic unit, namely between the individual and an aggregate. Household is the most frequent option in the literature because of the income sharing that occurs within the household and will be followed in this study.

A third important (and related) issue is the comparison of unlike units. Households with different compositions and dimensions have different needs, and therefore require distinct levels of income to achieve similar levels of well-being. The use of equivalence scales allows us to solve this problem through the calculation of the number of equivalent adults for each household. Specifically we follow the OECD modified scale in order to take into account the existence of economies of scale due to the share of housing and expenses. This scale gives a weight of 1 to the first adult, 0.5 to each of the remaining adults, and 0.3 to children under 14 years of age. This procedure accommodates the size and composition of the household.

A final methodological issue is the definition of the poverty line, i.e. the value below which an individual is classified as poor.[1] In this context, the choice is between using absolute or relative lines. In the first case, the threshold is defined without reference to the standard of living prevailing in the society. In the second case, that reference is taken into account. In the present study, we adopt the second option. 
2.2 Measurement of poverty and richness

The measurement of the three main dimensions of poverty (incidence, intensity, and severity) is usually done using the approach proposed by Foster et al. (1984):

$$
P_{\alpha}=\frac{\sum_{i=1}^{N}\left(G_{i} / Z\right)^{\alpha}}{N},
$$

with $\mathrm{N}$ being the total number of individuals in the population, $\mathrm{Z}$ the poverty line, and $\mathrm{G}_{\mathrm{i}}$ the poverty gap associated with individual $i$. $\mathrm{G}_{\mathrm{i}}$ will be zero if the income of $i\left(\mathrm{Y}_{\mathrm{i}}\right)$ is greater than or equal to $Z$, and $\left(Z-Y_{\mathrm{i}}\right)$ in the opposite case (i.e. when $i$ is poor). The parameter $\alpha(\alpha \geq 0)$ represents the sensitivity of the index to poverty. When $\alpha$ is 0,1 , and 2, we obtain, respectively, a measure of incidence, intensity, and severity of poverty (namely, the headcount index, the poverty gap index, and the poverty severity index). Similar measures can be defined to the evaluation of richness.

\subsection{An integrated approach}

Crespo et al. (2012) propose an integrated approach to the measurement of inequality, poverty, and richness. The first step of that methodology is a new income inequality indicator, which we will designate as INEQ, obtained at the household level. According to that measure, inequality is defined as the difference between the existing income distribution and the egalitarian one. Therefore, INEQ quantifies the percentage of total income that would be necessary to redistribute in order to eliminate inequality, and can be expressed as follows:

$$
\operatorname{INEQ}=\beta \sum_{\mathrm{i}=1}^{\mathrm{H}}\left|\psi_{\mathrm{i}}-\lambda_{\mathrm{i}}\right|
$$

in which:

$$
\psi_{\mathrm{i}}=\frac{\mathrm{Y}_{\mathrm{i}}}{\sum_{\mathrm{i}=1}^{\mathrm{H}} \mathrm{Y}_{\mathrm{i}}}
$$

and:

$$
\lambda_{\mathrm{i}}=\frac{\mathrm{D}_{\mathrm{i}}}{\sum_{\mathrm{i}=1}^{\mathrm{H}} \mathrm{D}_{\mathrm{i}}}
$$

We assume the most frequently used value for $\beta(\beta=0.5)$. Therefore, INEQ ranges between 0 and 1 . $H$ is the total number of households, $Y_{i}$ represents the total income of household $i$, and $\mathrm{D}_{\mathrm{i}}$ expresses the number of equivalent adults in that household. Therefore, $\psi_{\mathrm{i}}$ is the income weight of household $i$ and $\lambda_{\mathrm{i}}$ its weight in terms of equivalent adults. The minimum level of income inequality occurs when, for all households, these two shares are equal (i.e. when $\forall i, \psi_{i}=\lambda_{\mathrm{i}}$ ). Inequality increases with the difference, for each household, between its weight in terms of income and equivalent adults.

Taking INEQ as reference, the second step of the methodology is to define the criteria used to classify each household as poor, middle class (MC), or rich. This is accomplished by comparing what the household has in terms of income to what it should have, considering its size and composition, in order to obtain an equal distribution of resources[2]:
Poor? Rich?

Evidence for Portugal 
IJSE

40,6

$$
V_{i}=\left\{\begin{array}{l}
\text { RICH if } \frac{\psi_{i}}{\lambda_{i}}>\alpha \\
\text { MC if } \frac{1}{v} \leq \frac{\psi_{i}}{\lambda_{i}} \leq \alpha \\
\text { POOR if } \frac{\psi_{i}}{\lambda_{i}}<\frac{1}{v}
\end{array}\right.
$$

in which $\alpha, v \geq 1$.

Therefore, household $i$ is classified as rich if its share in total income exceeds $\alpha$ times its share in terms of equivalent adults. When the weight of household $i$ in total income is less than $1 / v$ the weight of that household in terms of equivalent adults, $i$ is classified as poor. In the intermediate cases, we classify the household as belonging to the middle class.

\section{Characterization of income groups - evidence for Portugal}

Following the procedure described above, we now seek to identify the way in which certain characteristics associated with households and the individual of reference of the household determine their probability of belonging to a given income group. In order to apply the method presented above, the following values for the parameters are assumed: $\beta=0.5, v=2$, and $\alpha=2$. As mentioned above, the value assumed for $\beta$ allows an easier interpretation of the inequality measure since in that case INEQ ranges between 0 and 1 . The values of $\alpha$ and $v$ are used to classify each household as rich, poor, or belonging to the middle class. In our empirical application we adopt a principle of symmetry between the poverty and the richness lines, assuming $v=\alpha=2$. Therefore, household $i$ is classified as rich when its share in total income is greater than or equal to twice its share in terms of equivalent adults.

We use micro-data from the Household Budget Survey (IDEF) of 2005/2006 provided by the Office of National Statistics (INE). IDEF is a large-dimension survey associated with a questionnaire filled in by households with detailed information on all collective and individual expenditures. It also includes demographic data, income data, and data on non-frequently consumed goods and services. The last wave of the survey was applied to a representative sample of the Portuguese economy with 10,403 households and a total of 28,359 individuals. Since for 31 individuals there is no information about their labor market state, the final sample was reduced to 10,372 households.

A multinomial logit model is estimated in order to identify how certain characteristics of households and the household's individual of reference influence their likelihood of being poor, middle class, or rich. The dependent variable, $T_{\mathrm{i}}$, is as follows:

$$
\mathrm{T}_{\mathrm{i}}=\left\{\begin{array}{l}
1 \text { if } \mathrm{V}_{\mathrm{i}}=\mathrm{MC} \\
2 \text { if } \mathrm{V}_{\mathrm{i}}=\mathrm{POOR} \\
3 \text { if } \mathrm{V}_{\mathrm{i}}=\mathrm{RICH}
\end{array}\right.
$$

Middle class is considered as reference. In Table I, we define the explanatory variables and present sample summary statistics.

We have estimated two different models: the non-spouse model and the spouse model. The difference between them concerns the variables related to the individual of reference. For the non-spouse model, these variables include: age, gender, 


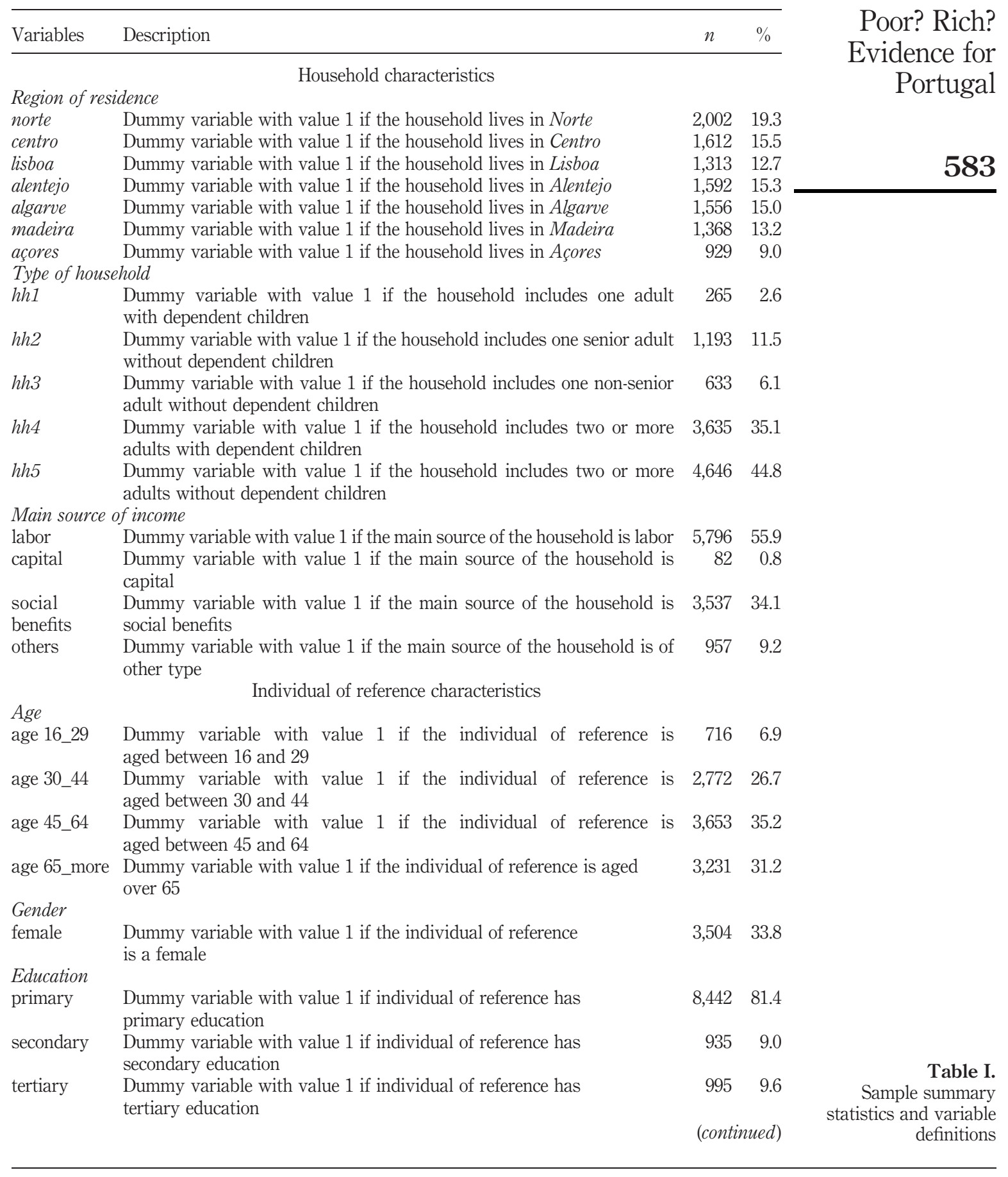


IJSE
40,6

584

Table I.

\begin{tabular}{llll} 
Variables & Description & $n$ & $\%$ \\
\hline
\end{tabular}

Labor market state

se_employer Dummy variable with value 1 if individual of reference is self-employed $\quad 562 \quad 5.4$ employer

se_ $\quad$ Dummy variable with value 1 if individual of reference is self-employed $\quad \begin{array}{lll}680 & 6.6\end{array}$

noemployees - no employees

employee Dummy variable with value 1 if individual of reference is an employee unemployed Dummy variable with value 1 if individual of reference is an unemployed inactive Dummy variable with value 1 if individual of reference is inactive Variables related to the spouse

$\begin{array}{llll}\text { married } & \text { Dummy variable with value } 1 \text { if the individual of reference is married } \quad 6,752 & 65.1\end{array}$

nespouse Dummy variable with value 1 if the spouse of the individual of reference $3,711 \quad 39.8$ is unemployed or inactive
$4,925 \quad 47.5$

$310 \quad 3.0$

$3,895 \quad 37.6$

Note: The reference group for each variable is the option with the highest frequency in the sample

educational level, and labor market state. In turn, the spouse model also considers the variables related to the spouse of the individual of reference, namely a dummy for the marital status of the individual of reference and another to reflect the labor-market state of the spouse. When this model is considered, the sample drops to 9,325 households because the spouse can only be identified when the individual of reference of the household is also the household's representative (i.e. the individual identified as such by the household's members) or the spouse of the representative.

The evidence for these two models is presented in Table II. In order to facilitate the assessment of the impact of the explanatory variables on the probability of being poor or rich, the coefficients presented in Table II correspond to relative risk ratios. Each of these ratios indicate by how many percent does the probability of occurrence of a given outcome is expected to change when there is a unit change in the explanatory variable, assuming that the remaining variables in the model are held constant.

Let us consider the non-spouse model. The first group of explanatory variables corresponds to household characteristics, namely region of residence, type of household, and main source of income. Regarding the region of residence, we see that living in Algarve or in Lisboa substantially reduces the probability of the household being poor and raises that of being rich. This is particularly true for the region of Lisboa (the most developed region of the country), where, by comparison to Norte (the reference region), the probability of being poor falls by more than $1 / 3$ and that of being rich is more than doubled. Living in Açores also substantially raises the probability of the household being rich.

Taking into account the type of household, the most striking element is the significant increase of the probability of being poor when the household has one adult with children or two or more adults with children. In both cases, the probability of being rich diminishes considerably. Concerning poverty, this finding is consistent with the results documented by Calvo et al. (2010) for the case of the Spanish economy, while the analysis developed by Peichl and Pestel (2010) for Germany confirms our findings regarding the impact of household type on richness.

The results from the main source of income are in line with expectations. Indeed, in comparison with households having labor as their main source of income, households 


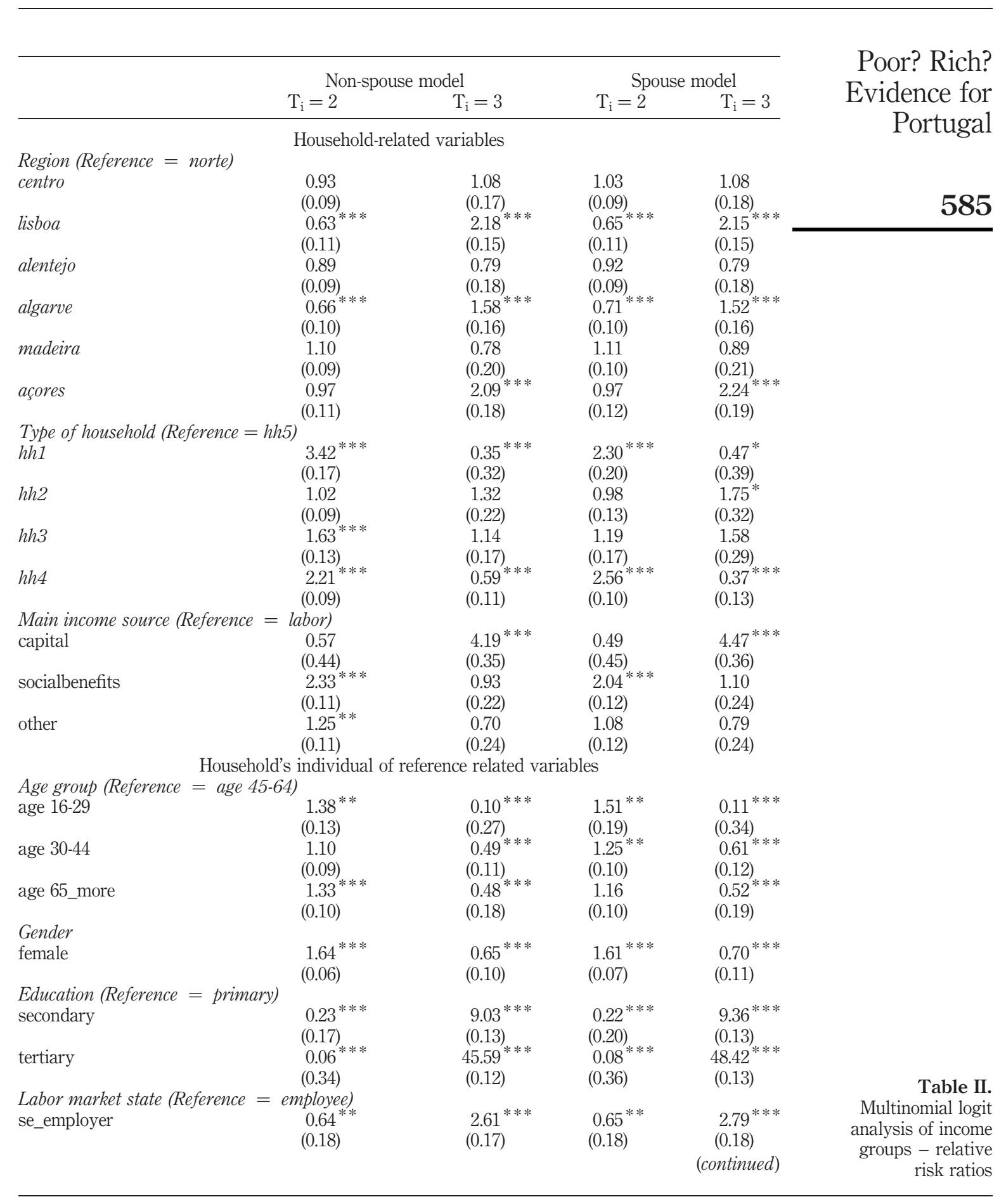


IJSE
40,6

586

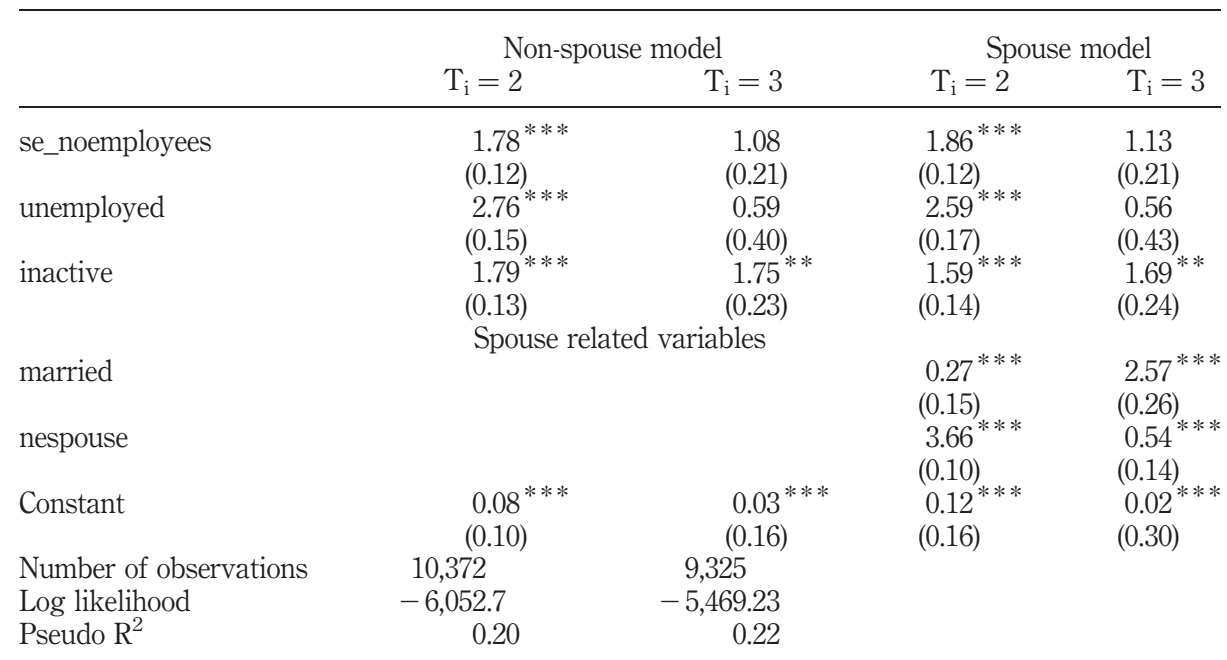

Table II.

Note: Significant at: ${ }^{*} 10,{ }^{* *} 5$ and ${ }^{* * *} 1$ percent

whose main source of income is capital income have a greater probability of being rich. On the contrary, there is a much greater probability (more than double) of households living mainly from social benefits to be poor and the same is true, despite the much lower magnitude, for those that have other main sources of income.

The second group of variables under scrutiny corresponds to a set of characteristics from the individual of reference of the household (age, gender, educational level, and labor market state).

The effect of age shows a clear pattern. The reference age group (45-64 years of age) has the greatest probability of richness and the lowest probability of poverty when compared to both 16-29 and over 64 age groups. According with Peichl and Pestel (2010) this effect can be associated with seniority-based pay. If the individual of reference is between 16 and 29 years of age, the probability of that household being poor rises 38 percent while it increases 33 percent for the age group of 64 and over, confirming the results obtained by Tsakloglou and Panopoulou (1998) for Greece. In any event, the probability of being rich diminishes to less than half in relation to the reference age group. Finally, the age group between 30 and 44 years of age shows greater probability of richness than that obtained for the reference age group while the probability of poverty is not different between these groups.

The gender evidence suggests that the probability of the household being poor rises 64 percent and that of being rich falls by 35 percent when the individual of reference of the household is a female. This is in line with the existence of differences between men and women in the labor market in terms of earnings, likelihood of promotions, and distribution across occupations (Altonji and Blank, 1999; Blau and Kahn, 2006). Several explanations for the less favorable situation of women can be advanced, including, for example, discrimination behaviors from employers, productivity differences, and preferences differences. These features are critical to understand the significant 
earnings differential documented, for instance, by Nopo et al. (2011) considering 64 countries from around the world.[3]

Education is one of the most important determinants of monetary (Card, 1999) and non-monetary benefits (Fabra and Camisón, 2009). More-highly educated individuals are able to perform tasks involving greater complexity, are more efficient in the process of job searching, and are better able to find jobs that meet their aspirations (Arrow, 1997). Our results reveal a huge impact of education variables, confirming the evidence presented by Tsakloglou and Panopoulou (1998), Brück et al. (2007) and Algieri and Aquino (2011). Additional levels of education from the individual of reference of the household enormously increase the probability of that household being rich and diminish that of being poor.

Finally, the labor market state of the individual of reference of the household is also decisive. As expected, when the representative is unemployed the probability of the household being poor increases significantly, confirming the prediction of Moller et al. (2003). On the other hand, being an employer has a strong increase in the probability of being rich and reduces by 36 percent that of being poor. An inactivity situation raises the probability of both richness and poverty. This last result is associated with the strong heterogeneity that can be found within this group in terms of critical aspects such as educational level and main source of income.

In addition to the initial model, we have also estimated, as mentioned above, a second model including variables associated with the spouse of the individual of reference (spouse model). According to this model, the influence of the variables already included in the first model does not show substantial changes, while the new variables provide important additional explanations of the phenomena under scrutiny. Indeed, when the individual of reference of the household is married, the probability of that household being rich rises and that of being poor falls. On the other hand, if the spouse is unemployed or inactive, the probability of the household being poor increases, while the probability of being rich drops by 46 percent.

\section{Final remarks}

Based on a methodology recently proposed to categorize the households according to their income levels, we evaluated the main determinants of poverty and richness. Using micro-data for Portugal, we concluded that the main determinant factors of the likelihood of poverty and richness are similar and include: household type, main source of income, education, and labor market state. The likelihood of being poor is greatest in larger households, living mainly from social benefits or whose head of household is unemployed. Furthermore, higher educational levels have strong implications, increasing the probability of richness and lowering the probability of poverty.

The results obtained in this paper have important policy implications since some key determinant factors of poverty and richness can be directly influenced by economic policy. In this context, some of the most important potential actions include:

- public policies aiming to increase the average educational level of the Portuguese population, not necessarily by allocating more financial resources to this area but mainly by adopting measures to increase the efficiency and effectiveness of the public spending on education (St. Aubyn et al., 2009);

- strengthened effort against gender discrimination in the labor market, as highlighted by the European Employment Strategy guidelines since 1998;
Poor? Rich?

Evidence for Portugal

587 
IJSE

40,6

588

- public policies that help to reduce regional inequalities; and

- public action to promote entrepreneurship (e.g. funding high-quality projects in key sectors, consultancy services, actions to reduce bureaucracy and improve legislation).

One of the limitations of the present study is the fact that due to data limitations it does not take into account the existence of inequality within the household. This is a common drawback to studies on this area and implies the under-estimation of the real degree of inequality existing in society (Haddad and Kanbur, 1990).

Regarding future research, we suggest three main directions. First, it would be useful to examine the evolution of the income inequality, poverty, and richness phenomena in the Portuguese economy. It would be especially interesting to assess the impact of the European economic and financial crisis in the last few years. Since the methodology applied in this study requires the consideration of specific values for some parameters (namely $v$ and $\alpha$ ), the performance of sensitivity analysis is a second research avenue. Third, it would be important to develop additional studies for other economies and periods considering the methodology applied in this study to verify the robustness of the conclusions obtained.

\section{Notes}

1. The definition of the richness line follows a similar procedure. In that case, the purpose is to define the value above which an individual is classified as rich.

2. We could also interpret equation (5) as comparing the income per equivalent adult of household $i$ with the income per equivalent adult for the economy as a whole.

3. On this topic, see also, for example, Davies and Joshi (1998) and De Silva (2008). Perrons (2010) provides a discussion on the influence of gender on poverty.

\section{References}

Algieri, B. and Aquino, A. (2011), "Key determinants of poverty risk in Italy", Rivista Italiana degli Economisti - The Journal of the Italian Economic Association, Vol. 3, pp. $411-430$.

Altonji, J. and Blank, R. (1999), "Race and gender in the labor market", in Ashenfelter, O. and Card, D. (Eds), Handbook of Labor Economics, Vol. 3C, North-Holland, Amsterdam, pp. 3143-3259.

Arrow, K. (1997), "The benefits of education and the formation of preferences", in Behrman, J. and Stacy, N. (Eds), The Social Benefits of Education, University of Michigan Press, Ann Arbor, MI, pp. 11-16.

Atkinson, A. and Piketty, T. (2010), Top Incomes: A Global Perspective, Oxford University Press, Oxford.

Atkinson, A., Piketty, T. and Saez, E. (2011), "Top incomes in the long run of history", Journal of Economic Literature, Vol. 49, pp. 3-71.

Bach, S., Corneo, G. and Steiner, V. (2009), "From bottom to top: the entire income distribution in Germany, 1992-2003", Review of Income and Wealth, Vol. 55 No. 2, pp. 303-330.

Blau, F. and Kahn, L. (2006), "The US gender pay gap in the 1990s: slowing convergence", Industrial \& Labor Relations Review, Vol. 60, pp. 45-66. 
Brück, T., Danzer, A., Muravyev, A. and Weißhaar, N. (2007), "Determinants of poverty during transition: household survey evidence from Ukraine”, IZA Discussion Paper No. 3228, Institute for the Study of Labor, Bonn.

Calvo, J., Sánchez, C. and Cortiñas, P. (2010), "Joint estimation of the characteristics and intensity of poverty in Spain: the case of imputed rent”, Economics Research International, pp. 1-17, Article ID 854634.

Card, D. (1999), "The causal effect of education on earnings", in Ashenfelter, O. and Card, D. (Eds), Handbook of Labor Economics, Vol. 3C, North-Holland, Amsterdam, pp. 1801-1863.

Cowell, F. (2011), Measuring Inequality, 3rd ed., Oxford University Press, Oxford.

Crespo, N., Moreira, S. and Simões, N. (2012), "An integrated approach for the measurement of inequality, poverty and richness", BRU-IUL Working Paper No. 12-03, Instituto Universitário de Lisboa (ISCTE - IUL), Lisbon.

Davies, H. and Joshi, H. (1998), "Gender and income inequality in the UK 1968-90: the feminization of earnings or of poverty?”, Journal of the Royal Statistical Society: Series A, Vol. 161, pp. 33-61.

De Silva, I. (2008), "Micro-level determinants of poverty reduction in Sri Lanka: a multivariate approach”, International Journal of Social Economics, Vol. 35 No. 3, pp. 140-158.

Fabra, M. and Camisón, C. (2009), "Direct and indirect effects of education on job satisfaction: a structural equation model for the Spanish case", Economics of Education Review, Vol. 28, pp. 600-610.

Foster, J., Greer, J. and Thorbecke, E. (1984), “A class of decomposable poverty measures", Econometrica, Vol. 52, pp. 761-776.

Haddad, L. and Kanbur, R. (1990), "How serious is the neglect of intra-household inequality?", Economic Journal, Vol. 100, pp. 866-881.

Haughton, J. and Khandker, S. (2009), Handbook on Poverty and Inequality, World Bank Publications, Washington, DC.

Moller, S., Bradley, D., Huber, E., Nielsen, F. and Stephens, J.D. (2003), "Determinants of relative poverty in advanced capitalist democracies", American Sociological Review, Vol. 68 No. 1, pp. 22-51.

Ñopo, H., Daza, N. and Ramos, J. (2011), “Gender earnings gaps in the world”, IZA Discussion Paper No. 5736, Institute for the Study of Labor, Bonn.

Peichl, A. and Pestel, N. (2010), "Multidimensional measurement of richness: theory and an application to Germany", IZA Discussion Paper No. 4825, Institute for the Study of Labor, Bonn.

Perrons, D. (2010), "Gender, work and poverty in high income countries", in Chant, S. (Ed.), The International Handbook of Gender and Poverty: Concepts, Research, Policy, Edward Elgar, Cheltenham, pp. 409-414.

Piketty, T. (2005), "Top income shares in the long run: an overview”, Journal of the European Economic Association, Vol. 3 Nos 2/3, pp. 382-392.

Piketty, T. and Saez, E. (2006), "The evolution of top incomes: a historical and international perspective", American Economic Review, Vol. 96 No. 2, pp. 200-205.

Roine, J., Vlachos, J. and Waldenström, D. (2009), "The long-run determinants of inequality: what can we learn from top income data?", Journal of Public Economics, Vol. 93, pp. 974-988.
Poor? Rich?

Evidence for

Portugal

589 
IJSE

40,6

\section{0}

St. Aubyn, M., Pina, A., Garcia, F. and Pais, J. (2009), "Study on the efficiency and effectiveness of public spending on tertiary education", European Economy - Economic Papers No. 390.

Tsakloglou, P. and Panopoulou, G. (1998), "Who are the poor in Greece? Analysing poverty under alternative concepts of resources and equivalence scales", Journal of European Social Policy, Vol. 8, pp. 213-236.

\section{About the authors}

Nuno Crespo is Professor at ISCTE-IUL; Researcher at UNIDE-IUL; and PhD in Economics at Universidade Técnica de Lisboa (ISEG-UTL).

Sandrina B. Moreira is Professor at ESCE-IPS; Researcher at UNIDE-IUL; and PhD in Economics at ISCTE-IUL. Sandrina B. Moreira is the corresponding author and can be contacted at: sandrina.moreira@esce.ips.pt

Nádia Simões is Professor at ISCTE-IUL; Researcher at UNIDE-IUL; and PhD in Economics at ISEG-UTL. 